9 Steere AC. Pachner AR, Malawista SE. Neurologic abnormalities of Lyme disease: successful treatment with high-dose intravenous penicillin. Ann Int Med 1983;99:767-72.

10) Gemignani F. Juvarra G, Calzetti S. Facial myokymia in the course of lymphocytic meningoradiculitis: case report. Neurolog. 1981:31:1177-80.

II Reik L. Steere AC. Bartenhagen NH, Shope RF. Malawista SE. Neurologic abnormalities of Lyme disease. Medicine (Bultimore) 1979:58:281-94.

12 Stiernstedt $G$. Tick-borne Borrelia infection in Sweden. Thesis, Stockholm 1985.

13 Pachner AR, Steere AC. The triad of neurologic abnormalities of Lyme disease: meningitis, cranial neuritis, and radiculoneuritis Neurology 1985;35:47-53.

14 Glaser JS. The pupils and accommodation (Chapter 8). In: Glaser JS, ed. Neuroophthalmology, vol 2. Duane TD: Harper \& Row, 1978:171-80.

15 Loewenfeld IE. Thomson HS. The tonic pupil. A re-evaluation. Am J Ophthalmol 1967: 63:46-56.

16 Thomson HS. Adie's syndrome: some new observations. Truns Am Ophthalmol Soc 1977:75:587-626.

17 Loewenfeld IE. The Argyll Robertson pupil 1869-1969: A critical survey of the literature. Surg Ophthalmol 1969;14:199-299.

18 Williams R, Harding AE. Pupillary light-near dissociation in paraproteinaemic neuropathy. A case report. Neuro-ophthalmology 1985:5:227-30.

19 Slyman JF. Kline LB. Dorsal midbrain syndrome in multiple sclerosis. Neurology 1981:31:196-18.

20 Rogers TD. Mitchell JD. Smith MA. Kean DM. Argyll Robertson pupil in multiple sclerosis. Neuro-ophthalmology 1985:5 223-5.

21 Kerr FWL. The pupil-functional anatomy and clinical correlation (Chapter 4). In: Lawton Smith J. ed. Neuro-ophthalmology: Vol 4 Mosby, 1968:69-76.

Accepted 19 June 1986.

Address for correspondence: Dr PJ Koudstaal, Department of Neurology. Dijkzigt Hospital. 40 Dr Molewaterplein. 3015 GD Rotterdam. The Netherlands.

\section{Oculogyric crisis in acute herpetic brainstem encephalitis}

Sir: So far oculogyric crisis has not been reported in acute herpetic brainstem encephalitis, although recently some 10 cases have been reported with its typical clinical features fully documented. We report a patient who showed this unique neurological symptom only at the onset of the disorder.
A 27 year old man was hospitalised because of disturbed consciousness on 11 February 1985. He had had sore throat and a fever of $38 \mathrm{C}$ for a week. On admission he was confused but followed simple commands. Bilateral abductor palsies, spasms of both masseters and the left orbicularis oris, and trismus were present. The deep tendon reflexes were bilaterally brisk with extensor plantar responses. He showed marked ataxia of the extremities. Meningeal signs were absent. On the second day, his extremities were markedly rigid, and dystonic postures, such as opisthotonus, were frequently observed. In addition to the bilateral impairment of upward and lateral gaze, conjugate downward spasmodic movements of the eyes (oculogyric crises) appeared. They consisted of slow tonic downward deviation of the eyes and dilatation of the pupils, each crisis lasting for several minutes (fig). They occurred spontaneously but could also be very easily induced by applying the noxious stimuli such as pinching. They were sometimes but not always accompanied by the exacerbation of the dystonic rigidity of the trunk and extremities. Adenine arabinoside $600 \mathrm{mg} /$ day was started and continued for 10 days. Over the next three days he was stuporous, though trismus, masticatory and facial spasms, and dystonic rigidity subsided gradually. The initial hyperreflexia was replaced by areflexia. Tracheostomy was performed but artificial respiration was not required. On the seventh day, as his consciousness began to improve, he showed marked bulbar palsy and flaccid tetraplegia, though he communicated by blinking (locked-in syndrome).
Although the oculogyric crises also began to subside, they still occurred even at this stage; they finally disappeared on the eighth day. Rapid recovery followed, and his condition returned to normal by mid March. One year later he is well with no signs or symptoms of Parkinsonism.

Cerebrospinal fluid (CSF) obtained on the second day showed: xanthochromia; lymphocytosis, $60 / \mathrm{mm}^{3}$; total protein, $61 \mathrm{mg} / \mathrm{dl}$ : IgG, $5.2 \mathrm{mg} / \mathrm{dl}$; and glucose, $86 \mathrm{mg} / \mathrm{dl}$. Electroencephalogram showed marked slowing of the background activity. Brainstem auditory evoked potentials showed normal waves 1,2 , and 3 , but waves 4 and 5 were absent bilaterally, suggesting a lesion in the upper pons. Computed tomographic scan and magnetic resonance imaging of the brain were unremarkable. Herpes simplex virus type I IgG immunofluorescence antibody titre in the CSF and serum were elevated to $1: 2$ and 1:160 respectively, both of which returned to normal later. Other viruses showed no remarkable elevation of the antibody titres. No virus was isolated from the throat and CSF.

Although the attack of dystonia and $\square$ downgaze in the acute phase of this case $\omega$ might mimic what is sometimes called a pon- $\overrightarrow{\mathbb{D}}$ G tine fit, the downgaze attack should be more $\frac{}{\mathbb{D}}$ 음 accurately called the oculogyric crisis for two reasons: (1) the clinical feature was typical, ${ }^{1}$ and (2) it was more prominent than $\Omega$ dystonia and frequently occurred alone, independently of dystonia. The oculogyric crisis and dystonia are closely related with each other: both are known to be seen frequently in postencephalitic Parkinsonism

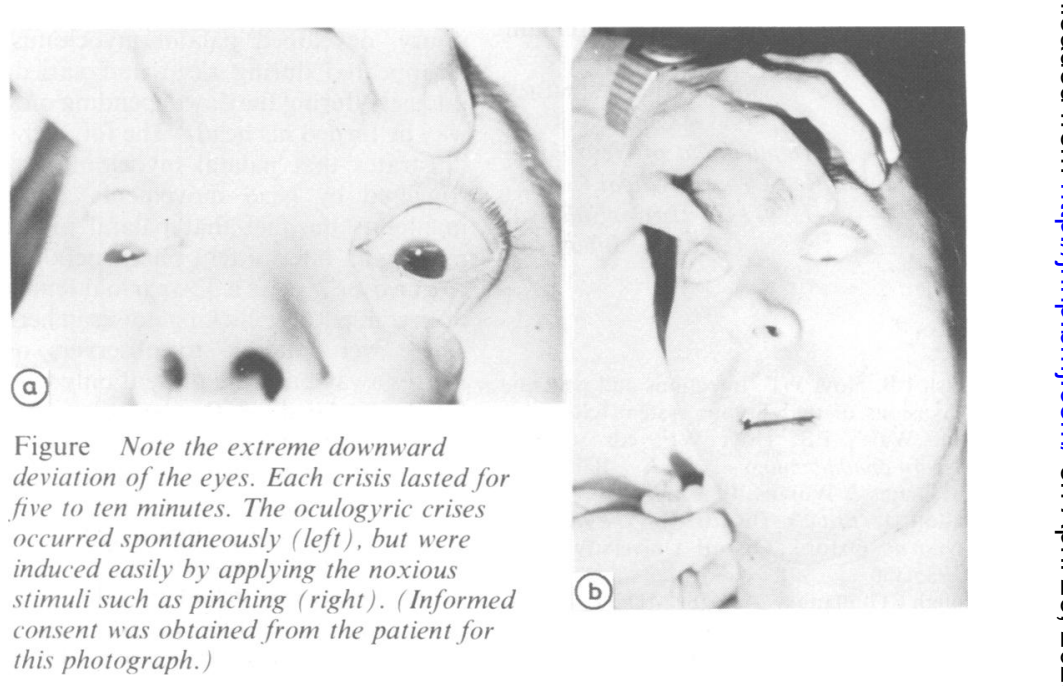


and antipsychotic drug intoxication. ${ }^{12}$ Although oculogyric crises due to encephalitides other than von Economo's encephalitis have been reported sporadically, they are usually seen in the chronic phase of the illness. $^{3}$ This case is quite unusual in that they occurred only at the onset of the acute brainstem encephalitis.

It is difficult to explain such an extreme degree of downgaze attack solely as a release phenomenon due to the impairment of upgaze: an irritative lesion near the downgaze centre or its pathways seems to be the more plausible explanation in this case. Although the precise anatomical localisation of the downgaze centre is still unknown, there is evidence that thalamic structures may exert some influence on downgaze, and that its pathways may run medial-dorsally to the red nuclei, more ventrocaudally than those for upgaze, in the midbrain. ${ }^{4}$

In this case, herpes simplex virus type 1 is suspected as the aetiological agent from the typical clinical features, the serological investigations, and the efficacy of adenine arabinoside. Recently acute herpetic brainstem encephalitis has been reported from all parts of the world. ${ }^{5-9}$ Although the similarity of Bickerstaff's encephalitis and acute herpetic brainstem encephalitis has been pointed out by some workers, ${ }^{6}$ the latter has some unique clinical features: symptoms suggesting the stimulative lesions in the brainstem such as trismus, masticatory spasm, facial spasm, blepharospasm, palatal myoclonus, and hiccup have been described only in acute herpetic brainstem encephalitis and not in Bickerstaff's encephalitis. 57910 Until the causal virus of Bickerstaff's encephalitis is identified, the relation between these two conditions will remain unclear.

KIICHIRO MATSUMURA MANABU SAKUTA Department of Neurology, Japanese Red Cross Medical Centre, 4-1-22 Hiroo, Shibuya, Tokyo, Japan 150

\section{References}

I Walsh FB, Hoyt WF. Infections and parasitic invasions of the nervous system (chap 10). In: Walsh FB, Hoyt WF, eds. Clinical Neuro-ophthalmology, vol $2 . \quad$ Baltimore: Williams \& Wilkins, 1969:1314-24.

2 Walton J. Brain's Diseases of the Nervous Sy:stem. Oxford: Oxford University Press, 1985:330.

3 Clough CG, Plaitakis A, Yahr MD. Oculogyric crises and Parkinsonism: a case of recent onset. Arch Neurol 1983;40:36-7.
4 Jacobs L. Anderson PJ. Bender MB. The lesions producing paralysis of downward but not upward gaze. Arch Neurol 1973:28:319-23.

5 Dayan AD. Gooddy W. Harrison MJG. Rudge $P$. Brain stem encephalitis caused by herpesvirus hominis. $B r$ Med $J$ 1972:4:405-6.

6 Ellison PH. Hanson PA. Herpes simplex: a possible cause of brain-stem encephalitis. Pediatrics 1977:59:240-3.

7 Fenton TR. Marshall PC. Cavanagh N. Wilson J. Marshall WC. Herpes-simplex infection presenting as brainstem encephalitis Lancet 1977:2:977-8.

8 Hirst LW, Clark AW. Wolinsky JS, et al. Downbeat nystagmus: a case report of herpetic brain stem encephalitis. $J$ Clin Neuroophthalmol 1983:3:245-9.

9 Hayashi $H$, Mizuno M. Herpes simplex encephalitis presenting as signs of brainstem lesions. Neurological Medicine (Tokio) 1984:20:186-9.

10 Bickerstaff ER. Brain stem encephalitis (Bickerstaff's encephalitis) (chap 31). In Vinken PJ, Bruyn GW, eds. Handhook of Clinical Neurology, vol 34. Amsterdam North-Holland Publishing Company. 1978:605-9.

Accepted 25 June 1986

\section{Palatal myoclonus influenced by head posture}

Sir: Palatal myoclonus is a segmental myoclonus syndrome which is often set apart from other movement disorders because of its persistence during sleep and throughout the life of the individual. ${ }^{1-3}$ Recently, however, Jacobs et al have reported the case of a 19-year-old man who, following a head injury, developed palatal myoclonus that disappeared during sleep and varied with intensity during the day depending on which way he turned his head. ${ }^{4}$ The following case illustrates that palatal myoclonus may be triggered by head movements and again highlights the fact that palatal myoclonus may be an intermittent phenomenon.

For over 2 years a 32-year-old female had noticed repetitive clicking noises in her head. These were audible to observers over 5 metres away but were present only when she tilted her head to the left or right. The intensity of the noises varied from day to day but could not be heard at all during ear or throat infections, to which she was especially prone. There were no other central nervous system abnormalities on examination, but inspection of the throat revealed irregular. bilateral, jumping movements of the palate and pharynx with her head in $45^{\circ}$ lateral flexion (left or right), but not at other timfs. A clicking noise synchronous with the myoclonic jerks could be heard at a rate $\oint^{f}$ approximately 120 per minute. After a f seconds both the jerking and the click hig

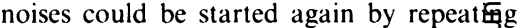
the movement of lateral flexion. The clickling noises were assumed to be arising from the pharynx or from opening and closing mo ments of the mouth of the Eustachian tube CT brain scan was normal.

The mechanism of generation of palatal myoclonus is unknown but post-mort $\overrightarrow{\mathrm{fm}}$ studies have demonstrated trans-synaptic hypertrophic degeneration of the inferior olivary nuclei due to a lesion of one of afferent inputs, the dentato-olivary pastway. ${ }^{7}$ The switching on of palatal m clonus in our patient by certain head modements suggests that other afferent pathwás to the inferior olivary nuclei may be important in modifying the expression $\rightarrow f$ this movement disorder; in this case p $\overrightarrow{\boldsymbol{w}}$ prioceptive input via the cuneate nucle may be pertinent.

DOC COR $\frac{\partial}{\mathrm{B}} \mathrm{N}$ AC WILLIATS Queen Elizabeth Hospicud, Edghäsicon Birmingham B15 2TH

References and pathophysiology of myoclonus. In: ders. London: Butterworth Scientific, +98 217-9.

2 Bonduelle $M$. The myoclonias. In: Vinken B. Bruyn GW, eds. Handhook of Clinical $N$ rology. Vol 6. Diseases of the Basal Gangt Amsterdam: North Holland Publishm Company, 1968

3 Guillain $G$. The syndrome of synchron胥 and rhythmic palato-paryngo-laryngoculo-diaphragmatic myoclonus. Proc Med 1938;31:1031-8.

4 Jacobs L, Newman RP, Bozian D. Dis pearing palatal myoclonus. Neurols, 1981;31:784-9.

5 Chadwick DL, Macbeth R. Rhythmic pala myoclonus. J Laryngol Oto/ 1953;67:301- $\mathrm{R}$.

6 Gautier JC, Blackwood W. Enlargement of inferior olivary nucleus in association with lesions of the central tegmental tract or dentate nucleus. Brain 1961:84(3):341-61을

7 Lapresle J. Rhythmic Palatal Myoclonus añ the Dentato-Olivary Pathway. J Neu\&l 1979;220:223-30.

8 Barr ML, Kiernan JA. The Human Nerve System: An Anatomical Viewpoint. 4th Philadelphia: Harper and Row, 1983:95. N

Accepted 10 July 1986 